\title{
Comment
}

Neuroepidemiology 2013;40:225-226

DOI: $10.1159 / 000343960$

\section{Nonarteritic Ischemic Optic Neuropathy and Other Vascular Diseases}

Gad Dotan Amos D. Korczyn

Departments of Ophthalmology and Neurology, Sackler School of Medicine, Tel Aviv University, Ramat Aviv, Israel

Nonarteritic ischemic optic neuropathy (NAION) is the most common optic neuropathy in adults older than 50 years of age and the reported annual incidence in this age group is 2.3-10.2 cases per 100,000 [1]. Known risk factors have been described for this condition, including hypertension, diabetes mellitus, ischemic heart disease, hypercholesterolemia and tobacco use $[2,3]$. Other associated conditions include hematologic abnormalities such as hyperhomocysteinemia and possibly the use of performance-enhancing medications $[4,5]$. Further studies to investigate for the presence of a hypercoagulable state should be considered in patients who do not have the typical risk factors or the typical clinical course, such as young patients or simultaneously bilateral events.

Recurrence of NAION in the same eye is uncommon [6]. However, the risk of second eye involvement within 5 years from the first event is approximately $15 \%$ in the general population and $20 \%$ in diabetics [7]. Optic nerve decompression surgery has been investigated with disappointing results [8]. As currently there is no effective treatment for this condition and the visual loss is usually permanent, many patients are anxious that the same event will occur in their other eye and to the possibility of other nonocular ischemic events. This has led to the common practice of prescribing aspirin; however, it is unclear whether this therapy reduces the risk of fellow eye events. In the study of Kupersmith et al. [9], the use of aspirin taken two or more times per week decreased the incidence of second eye involvement (17.5 vs. $53.5 \%$ ). However, another study found no significant difference at 5 years [10]. In patients who develop NAION while taking low-dose aspirin, the common practice is to increase the dosage of the drug, but there is no data to prove the benefit of this approach.

Previous reports on the risk of cardiac and cerebral vascular events following NAION have attained contradictory results. In a paper published in this issue, Hasanreisoglu et al. [11] found that the risk of cardiovascular and cerebrovascular events following NAION is similar to that in the general population. This conclusion seems almost intuitive, as one can speculate why an ischemic event that occurred in the eye should influence the occurrence of other vascular events besides reflecting the presence and severity of the risk factors. Salomon et al. [12] reported similar findings of no increased risk for cardiac and cerebral vascular events following NAION. On the other hand, other authors have reported dif- ferent results $[13,14]$. For example, Hayreh et al. [14] reported that the risk of cerebrovascular events for patients with hypertension and diabetes who developed NAION was greater than in the general population. However, this study did not specify whether the ocular ischemic event was an independent risk factor.

In their study, Hasanreisoglu et al. [11] divided their patients into diabetics and nondiabetics and compared their risk for cardiac and vascular events to historical control data from the Farmington, UK Prospective Diabetes Study (UKPDS) and the National Vascular Disease Prevention Alliance (NPDPA) data. As expected, in diabetics, the risk for cardiac and vascular events was higher than in nondiabetics. However, the presence of NAION was not an independent risk factor and as such did not influence the occurrence of these systemic complications. There is, nevertheless, a significant difference in the type of blood vessels involved in these conditions. NAION is a disease of smaller blood vessels, the branches of the short posterior ciliary arteries, whereas myocardial infarction and ischemic stroke result from the obstruction of intermediate-sized arteries. It would have been interesting to note, on magnetic resonance imaging, the rate of occurrence of lacunar infarcts of the brain of these patients which result from involvement of arteries of comparable size.

The results found by Hasanreisoglu et al. [11] in their study are somewhat reassuring to the patient with NAION. As it is impossible to improve vision in the affected eye or to prevent the occurrence of the same event in the other eye, it is important to emphasize to the patients the positive aspects as much as possible: firstly, the risk that the second eye will be similarly affected within the next several years is significantly less than the risk that it will not become affected. Furthermore, there is no evidence for an increased risk of cardiac and cerebral ischemia following the ocular event.

\section{References}

1 Hattenhauer MG, Leavitt JA, Hodge DO, Grill R, Gray DT: Incidence of nonarteritic anterior ischemic optic neuropathy. Am J Ophthalmol 1997;123:103-107.

-2 Jacobson DM, Vierkant RA, Belongia EA: Nonarteritic anterior ischemic optic neuropathy, a case-control study of potential risk factors. Arch Ophthalmol 1997;115:1403-1407.

3 Salomon O, Huna-Baron R, Kurtz S, Steinberg DM, Moisseiev J, Rosenberg N, Yassur I, Vidne O, Zivelin A, Gitel S, et al: Analysis of prothrombotic and vascular risk factors in patients with nonarteriticanterior ischemic optic neuropathy. Ophthalmology 1999;106:739-742.

-4 Pianka P, Almog Y, Man O, Goldstein M, Sela BA, Loewenstein A: Hyperhomocystinemia in patients with nonarteritic anterior ischemic opticneuropathy, central retinal artery occlusion, and central retinal vein occlusion. Ophthalmology 2000;107:1588-1592.

5 Pomeranz H, Smith K, William H, Egan R: Sildenafil-associated nonarteritic anterior ischemic optic neuropathy. Opthalmology 2002;109: 3:584-587.

\section{KARGER}

Fax +4161306 1234

E-Mail karger@karger.ch

www.karger.com
C 2013 S. Karger AG, Basel

0251-5350/13/0403-0225\$38.00/0

Accessible online at:

www.karger.com/ned
Prof. Amos D. Korczyn, MD, MSc

Department of Neurology

Sackler School of Medicine, Tel Aviv University

Ramat Aviv 69978 (Israel)

E-Mail Amoskor@tau.ac.il 
6 Hayreh SS, Podhajsky PS, Zimmerman B: Ipsilateral recurrence of nonarteritis anterior ischemic optic neuropathy. Am J Ophthalmol 2001; 132:734-742.

$>7$ Newman NJ, Scherer R, Langenberg P, Kelman S, Feldon S, Kaufman D, Dickersin K, Ischemic Optic Neuropathy Decompression Trial Research Group: The fellow eye in NAION: report from the Ischemic Optic Neuropathy Decompression Trial follow-up study. Am J Ophthalmol 2002; $134: 317-328$.

-8 The Ischemic Optic Neuropathy Decompression Trial Research Group: Optic nerve decompression surgery for nonarteritic anterior ischemic optic neuropathy (NAION) is not effective and may be harmful. JAMA 1995;273:625-632.

9 Kupersmith MJ, Frohman L, Sanderson M, Jacobs J, Hirschfeld J, Ku C, Warren FA: Aspirin reduces the incidence of second eye NAION: a retrospective study. J Neuroophthalmol 1997;17:250-253.

10 Beck RW, Hayreh SS, Podhajsky PA, et al: Aspirin therapy in nonarteritic anterior ischemic optic neuropathy. Am J Ophthalmol 1997;123: 212-217.
1 Hasanreisoglu M, Robensthtok E, Ezrahi D, Stiebel-Kalish H: Do patients with non-arteritic ischemic optic neuritis have increases risk for cardiovascular and cerebrovascular events? Neuroepidemiology 2013; 40:220-224.

12 Salomon O, Huna-Baron R, Steinberg DM, Kurtz S, Seligsohn U: Role of aspirin in reducing the frequency of second eye involvement in patients with non-arteritic anterior ischaemic optic neuropathy. Eye 1999; 13:357-359.

13 Repka MX, Savino PJ, Schatz NJ, Sergott RC: Clinical profile and longterm implications of anterior ischemic optic neuropathy. Am J Ophthalmol 1983;96:478-483.

14 Hayreh SS, Joos KM, Podhajsky PA, Long CR: Systemic diseases associated with nonarteriticanterior ischemic optic neuropathy. Am JOphthalmol 1994;118:766-780. 